\title{
Shifting Age of Peak Binge Drinking Prevalence: Historical Changes in Normative Trajectories Among Young Adults Aged 18 to 30
}

\author{
Megan E. Patrick (D), Yvonne M. Terry-McElrath (D), Stephanie T. Lanza, Justin Jager, \\ John E. Schulenberg, and Patrick M. O'Malley
}

\begin{abstract}
Background: This study examined the extent to which the developmental pattern of prevalence of binge drinking in the past 2 weeks from ages 18 through 30 has changed across 29 cohorts of U.S. young adults, and whether the changes differed by gender.

Methods: Analyses used national longitudinal data from 58,019 12th-grade students (from graduating high school classes 1976 to 2004) participating in the Monitoring the Future study followed through modal age 30 (with age 29/30 data collected from 1987 to 2016). Weighted time-varying effect modeling was used to model cohort group differences in age-related patterns of binge drinking.

Results: The age of peak binge drinking prevalence increased across cohorts (from age 20 in 1976 to 1985 to 22 in 1996 to 2004 for women, and from 21 in 1976 to 1985 to 23 in 1996 to 2004 for men). Historical change in the developmental pattern of binge drinking across all ages of young adulthood differed for men and women. Even after controlling for key covariates, women in the more recent cohort group reported significantly higher binge drinking prevalence than women in earlier cohorts from ages 21 through 30. Men in the more recent cohort group reported higher binge drinking prevalence at ages 25 to 26 , but prevalence levels then converged to those seen in earlier cohort groups by age 30 .

Conclusions: An older age of peak binge drinking and a decreased rate of decline in the prevalence of binge drinking in later young adulthood among more recent cohorts have resulted in an extension of individual and societal risks associated with binge drinking, particularly for women, across young adulthood. High-risk alcohol use prevention efforts are needed throughout at least the third decade of life.
\end{abstract}

Key Words: Binge, Pattern, Gender Differences.

$\mathrm{T}$ HE INDIVIDUAL AND societal risks associated with binge drinking are well recognized (e.g., Centers for Disease Control and Prevention, 2017; Naimi et al., 2003; World Health Organization, 2014). Binge drinking is often defined as 5+ drinks per occasion (e.g., Dawson et al., 2015; Miech et al., 2018; Schulenberg et al., 2018; Substance Abuse and Mental Health Services Administration, 2018). Young adults (and those around them) are at higher risk for negative consequences resulting from binge drinking compared to other age groups. The normative developmental pattern of binge drinking involves escalation from late adolescence into the early 20 s, followed by some level of

From the Institute for Social Research (MEP, YMT-M, JES, PMO), University of Michigan, Ann Arbor, Michigan; Health and Human Development (STL), The Pennsylvania State University, State College, Pennsylvania; and T. Denny Sanford School of Social and Family Dynamics (JJ), Arizona State University, Tempe, Arizona.

Received for publication August 6, 2018; accepted November 26, 2018. Reprint requests: Megan E. Patrick, PhD, Institute of Child Development and Institute for Translational Research in Children's Mental Health, University of Minnesota, 1100 Washington Avenue South, Minneapolis, MN 55415; Tel.: 612-624-8063; Fax: 612-624-3049; E-mail:mpatrick@umn.edu

(C) 2018 by the Research Society on Alcoholism.

DOI: 10.1111/acer.13933 moderation or "maturing out" thereafter (Bachman et al., 1997, 2002; Maggs and Schulenberg, 2004; Patrick et al., 2016; Schulenberg et al., 2018; Substance Abuse and Mental Health Services Administration, 2017). This normative developmental pattern is distinct from historical fluctuations in binge drinking prevalence. That is, regardless of whether historical trends in binge drinking during late adolescence have increased, decreased, or remained stable, binge drinking has been observed to increase from age 18 through the early 20 s and then decrease through the late 20 s. The extent to which these developmental patterns in the prevalence of binge drinking have changed historically has not been closely examined.

It is recognized that etiology, in terms of course of alcohol and other drug use, varies by history (Schulenberg et al., 2014), with important cohort-related changes in the normative developmental pattern of average frequency of binge drinking during the transition to adulthood (e.g., Jager et al., 2013, 2015). Specifically, using national U.S. longitudinal data from 28 high school class cohorts (1976 to 2003), latent growth curve models showed that binge drinking frequency accelerated more quickly across ages 18 to 22 (Jager et al., 2013, 2015) and decelerated more slowly across ages 22 to 26 (Jager et al., 2015) for recent cohorts compared to earlier cohorts. Therefore, more recent cohorts reported lower 
frequency binge drinking at age 18, but higher frequency binge drinking at age 26 relative to past cohorts. The focus of the current study, however, is on prevalence of binge drinking - that is, how many young adults report any binge drinking in the past 2 weeks. A focus on changing prevalence results in the ability to examine variation in the proportion of the population at risk for negative alcohol-related consequences at a given age. Change in the frequency of binge drinking, on the other hand, does not allow for distinguishing between changes in the rate of binge drinking among drinkers from changes in the proportion of the population engaging in any binge drinking. That is, an increase in average binge drinking frequency may be the result of a subset of drinkers increasing how often they binge drink or of a greater proportion of the population engaging in any binge drinking.

Historical changes in the developmental pattern of binge drinking prevalence have meaningful implications for expected individual and societal costs associated with alcohol use, and thus important implications for research, prevention, and intervention efforts. More young adults initiating binge drinking in recent years would help explain why the average frequency of binge drinking from ages 18 to 22 increased in Jager and colleagues (2013); it would also mean that important reductions in harms and costs associated with past decreases in adolescent binge drinking have not necessarily extended to lower risk behavior in young adulthood. Delayed participation in binge drinking is beneficial in that adolescent binge drinking is associated with impairments in memory, decision making, reasoning, attention, and academic performance (Alfonso-Loeches and Guerri, 2011; Crego et al., 2009; Squeglia et al., 2012). However, brain development (particularly aspects related to cognition, decision making, and neural connectivity) continues at least through age 30 (Lebel and Beaulieu, 2011; Pujol et al., 1993; Sowell et al., 1999; Tamnes et al., 2010; Walhovd et al., 2005) suggesting that just delaying alcohol use onset and escalation until early adulthood does not fully avoid the potential negative impacts of alcohol on maturation. One key indicator of the ages at which young adult risk is most concentrated is the age of peak binge drinking prevalence. If this age has changed historically, we need to adjust our prevention and intervention efforts accordingly. In particular, if the age of peak binge drinking has increased, then the risks associated with an increasing population of binge drinkers would extend further into young adulthood. Conversely, if the age of peak binge drinking prevalence has decreased historically, then the risk associated with binge drinking would remain even more highly concentrated in early young adulthood as the period of highest risk would not extend as far into the 20s.

Vulnerability to negative consequences from alcohol use and binge drinking (such as alcohol-related health and psychosocial consequences) is higher for women than men (Dir et al., 2017). The normative developmental pattern of binge drinking has been understood to generally follow similar patterns for both men and women, but with higher prevalence levels for men (Patrick et al., 2016; Schulenberg et al., 2018). Yet, the gap between men and women in overall alcohol use (including binge drinking) has decreased notably in recent decades (e.g., Dir et al., 2017; Erol and Karpyak, 2015; Schulenberg et al., 2018; Slade et al., 2016; White et al., 2015). There is some evidence that women may have a greater rate of increase in binge drinking frequency from ages 18 to 22 than men (Jager et al., 2013) and that the rate of decline in binge drinking prevalence across ages 35 to 85 is slower for women than for men (Karlamangla et al., 2006). These studies suggest that there may be differences in agerelated patterns of binge drinking prevalence for men and women, including different ages of concentrated risk indexed by the age of peak binge drinking prevalence.

Historical change in binge drinking prevalence may be associated with fundamental shifts in the underlying behavior, with responses to changes in policy and social roles, or with shifting demographic characteristics. During the earlyto mid-1970s, the majority of U.S. states lowered their minimum legal drinking age (MLDA) to under 21 years of age (Wagenaar and Toomey, 2002). However, public concern regarding increasing negative alcohol-related consequences (e.g., traffic crashes) led to calls to reinstate the MLDA of 21, and the federal government enacted the Uniform Drinking Age Act of 1984. By 1988, all U.S. states had returned to a MLDA of 21 (Wagenaar and Toomey, 2002). Evaluations of adolescent and young adult alcohol use in these changing policy environments found that lower MLDA was associated with significantly higher alcohol consumption (O'Malley and Wagenaar, 1991; Wagenaar and Toomey, 2002). Thus, one would expect to see higher binge drinking prevalence during early young adulthood for cohorts from the 1970s through mid-1980s. For both genders, historical differences in age 18 binge drinking from 1976 to 2004 were significantly linked to MLDA; for males only, historical differences in age 18 to 22 growth in binge drinking from 1976 to 2004 were also significantly linked to MLDA (Jager et al., 2015). MLDA will be included as a control in the current study.

Other possible contributors to historical variation in binge drinking prevalence include historical variation in social roles associated with alcohol use (e.g., parenthood, marriage, college attendance, employment status; Bachman et al., 2002) and the racial/ethnic composition of the U.S. population. Specifically, there have been historical increases in the percentages of young adults in social roles associated with higher alcohol use, such as being a college student (National Center for Education Statistics, 2018), not married (US Census Bureau, 2017), not a parent (Khandwala et al., 2017; Mathews and Hamilton, 2016; Matthews and Hamilton, 2009), and not employed full-time (Taylor et al., 2012) or at all (US Bureau of Labor Statistics, 2004-2017). Delays in marriage and parenthood and decreasing employment among those of younger ages may be contributing to the extension of peak binge drinking age across cohorts. Adjustment for changes in such social roles explains some historical 
change in the binge drinking frequency growth rate during early adulthood, but not past the age of 22 (Jager et al., 2015). The racial/ethnic composition of the United States also has changed dramatically. Since the mid-1970s, the proportion of the U.S. population identifying as White has decreased from $81 \%$ to $62 \%$ (Pew Research Center, 2015), and alcohol consumption is generally higher among White than non-White individuals (Delker et al., 2016; Miech et al., 2018; Terry-McElrath and Patrick, 2018). We include these sociodemographic indicators as controls in order to evaluate the extent to which these changing factors account for observed historical changes.

Analytic methods used to model the developmental pattern of binge drinking have often employed growth curve modeling with longitudinal data (e.g., Conrod et al., 2008; Jager et al., 2013; Patrick and Schulenberg, 2011; Patrick et al., 2016; Wood et al., 2010) or age-period-cohort models with cross-sectional data (e.g., Kerr et al., 2009). These methods are very useful but impose parametric forms for all associations and typically assume that the observed associations are consistent over time (see also Patrick et al., 2017a). When seeking to determine whether the strength of a particular association changes across time, time-varying effect modeling (TVEM) provides an alternative modeling approach (Lanza et al., 2016; Li et al., 2015; Tan et al., 2012). TVEM models (described in greater detail below) allow for not only the behavior of interest (i.e., binge drinking) to change across time (i.e., age), but also the possible effects of covariates to change across time (e.g., gender over age), with no assumptions of parametric form for the observed changes.

\section{The Current Study}

Previous studies that examined the average frequency of binge drinking through the mid-20s with latent growth curve models (Jager et al., 2013, 2015) provided important insights into historical change in alcohol use epidemiology. The current study extends such work by (i) expanding the age range to 18 to 30 , (ii) testing for gender differences in historical changes and the extent to which controlling for key covariates explains observed gender differences, (iii) focusing on prevalence rather than frequency of binge drinking, (iv) using a nonparametric data analysis technique, and (v) focusing on peak age of binge drinking. The current study uses TVEM to consider cohort by gender variation in developmental patterns of binge drinking prevalence from ages 18 through 30 using national panel data from 29 high school class cohorts. We give particular emphasis to cohort variation in the peak age of binge drinking prevalence following high school graduation.

\section{MATERIALS AND METHODS}

\section{Participants}

Data from the national Monitoring the Future (MTF) study included nationally representative cohorts of U.S. 12th-grade students, a portion of whom were followed longitudinally (for detailed methodology, see Bachman et al., 2015; Miech et al., 2018; Schulenberg et al., 2018). Each year since 1975, nationally representative samples of approximately 15,000 12th graders (modal age 18) from about 130 schools in the contiguous United States were surveyed using self-administered paper surveys, typically during a normal class period. From each annual cohort, a subsample of about 2,400 was selected for longitudinal follow-up; drug users were oversampled. Respondents were randomly assigned to begin biennial followup either 1 year later (at model age 19) or 2 years later (at modal age 20) using mailed questionnaires. Therefore, young adult data were provided at a maximum of 7 time points per person, at modal ages $18,19 / 20,21 / 22,23 / 24,25 / 26,27 / 28$, and $29 / 30$. The University of Michigan Institutional Review Board approved the study.

Analysis was limited to cohorts with the opportunity to complete all baseline and follow-up surveys through age 29/30. The analytic sample included respondents from the 29 12th-grade cohorts of 1976 to 2004 (birth cohorts of approximately 1958 to 1986) who were eligible to respond at age 29/30 (age 29/30 data collected during 1987 to 2016). A total of 70,843 individuals were selected for follow-up participation from the relevant cohorts; 58,076 respondents $(82.0 \%)$ participated in at least 1 of the 6 follow-up data collection efforts, and 58,019 (99.9\% of those who participated in a follow-up) provided data on binge drinking on at least 1 occasion. The mean number of available measurements on binge drinking per respondent in the resulting analytic data set was 5.3 (range of 1 to 7 ). The analytic sample was $53.7 \%$ female, and $78.5 \%$ White, $9.2 \%$ Black, $6.0 \%$ Hispanic, $2.4 \%$ Asian, and $3.9 \%$ other race/ethnicity. Attrition adjustments are discussed below.

\section{Measures}

On each survey, respondents were asked to think back over the last 2 weeks when answering the question, "How many times have you had five or more drinks in a row?" with response options of none, once, twice, 3 to 5 times, 6 to 9 times, and 10 or more times. Binge drinking was coded as a dichotomous variable indicating any consumption of 5 or more drinks during the last 2 weeks (yes, no).

Covariates at 12 th grade included self-reported gender (male, female) and race/ethnicity (coded for analysis as a dichotomy of non-White vs. White). Time-varying covariates self-reported at each follow-up from age 19 through 30 included college attendance (currently attending a 4-year college vs. not), employment (having at least 1 full-time or part-time job vs. no paid work), marital status (married vs. not), and parental status (any children vs. no children). Age was based on the modal year of age per survey from 18 to 30 . State MLDA was coded based on the state and year in which the respondent answered the 12th-grade survey and was used as a continuous measure (range 18 through 21; policy data were obtained from Hedlund et al., 2001; Hoxie and Skinner, 1987).

Cohort (indicating year of 12th-grade survey) was coded into 3 nonoverlapping groups: 1976 to 1985,1986 to 1995 , and 1996 to 2004. The decision to define cohort groups in this way was based on 2 considerations. First, these groups reflect distinct changes in age 18 binge drinking prevalence (Miech et al., 2018): 1976 to 1985 were cohorts with higher prevalence, 1986 to 1995 were cohorts with decreasing 12th-grade prevalence, and 1996 to 2004 were cohorts with more stable 12th-grade prevalence. Second, prior research (Jager et al., 2015) indicated that the historical rate of change in binge drinking frequency from ages 18 to 26 differed meaningfully, with the reported differences generally following the 3 cohort groups defined here. Analyses for the current paper also showed that, averaged across age, binge drinking and covariate prevalence/means differed significantly across these 3 cohort groups (see Table S1). Similar levels of within-cohort group variability were evidenced by similar standard errors for cohort group specific binge drinking and covariate estimates other than race/ethnicity (which showed increasing variability 
over time) and MLDA (which showed decreasing variability over time).

\section{Data Analysis}

All analyses were conducted using SAS 9.4 (SAS Institute Inc., Cary, NC). TVEM was used to statistically model regression coefficients (i.e., intercepts and slopes) as flexible, nonparametric functions of age. In other words, prevalence levels and associations between 1 or more covariates and an outcome were estimated across age in a smooth manner, making no assumptions about the parametric forms of the coefficient functions (Lanza et al., 2014; Li et al., 2015; Tan et al., 2012). In all models reported here, time was operationalized as modal age in years. TVEM models were fit using the SAS macro \%WeightedTVEM (v. 2.6.0) (Dziak et al., 2014; Weighted TVEM SAS Macro, 2017). The coefficient functions (presented in figures) are expressed as odds ratios (ORs) or adjusted ORs (for bivariate or multivariable associations) with pointwise 99\% confidence intervals (CIs) for each smoothed point along continuous age (an alpha of 0.01 was used in order to yield more conservative significance testing). Coefficients were significant at $p<0.01$ at points where CIs do not contain 1.0. The optimal number of knots (corresponding to smoothness) for each coefficient function was selected based on comparison of pseudolikelihood Akaike information criterion and Bayesian information criterion values from unpenalized B-spline regression models (Dziak et al., 2017).

Before examining the main research questions, an intercept-only TVEM was used to show the overall developmental pattern of binge drinking prevalence from ages 18 to 30 for all cohorts and genders combined to compare with previously reported studies. Then, to address the main research questions, binge drinking was regressed simultaneously on cohort, gender, and gender-by-cohort interaction terms. Based on significant gender-by-cohort interactions, genderspecific models then examined whether there were significant cohort effects for men and women separately. The TVEM including cohort group, gender, and gender-by-cohort interactions using 1976 to 1985 as the referent category can be written as:

$$
\begin{aligned}
\ln \left(\frac{P\left(\mathrm{BINGE}_{i t}=1\right)}{1-P\left(\mathrm{BINGE}_{i t}=1\right)}\right)= & \beta_{0}(t)+\beta_{1}(t){\text { Cohorts } 86 \text { to } 95_{i}} \\
& +\beta_{2}(t) \text { Cohorts96to0 }_{i}+\beta_{3}(t) \text { Male }_{i} \\
& +\beta_{4}(t) \text { Male }_{i} *{\text { Cohorts } 86 \text { to } 5_{i}} \\
& +\beta_{5}(t) \text { Male }_{i} * \text { Cohorts96to0 }_{i}
\end{aligned}
$$

where $t$ indicates continuous age and $i$ denotes data for individual $i$. Here, $\beta_{0}$ is the intercept, reflecting the log-odds of binge drinking across age for females in the earliest cohort group; $\beta_{1}$ and $\beta_{2}$ are the slope functions describing the age-varying association between cohort group (referent $=$ cohort group 1976 to 1985) and binge drinking among females; $\beta_{3}$ is the slope function describing the agevarying association between gender and binge drinking among young adults in the earliest cohort group (referent = females); and $\beta_{4}$ and $\beta_{5}$ are the slope functions describing the age-varying gender differences in cohort group differences in the log-odds of binge drinking. Finally, gender-specific multivariable models were run for ages 19 to 30 specifying time-varying associations for cohort group as well as time-varying effects of control variables including race/ ethnicity, college attendance, employment, marital status, parental status, and MLDA. Multivariable models were limited to ages 19 to 30 because several measures (particularly college attendance, but also marital and parental statuses) gained meaningful variance only after completion of high school. A total of 56,316 individuals (97.1\% of those included in gender/cohort group models) provided data on all covariates and were included in multivariable models.
All analyses accounted for clustering of repeated measures within individuals by providing robust standard errors using Taylor linearization (Dziak et al., 2017). Further, all analyses were weighted using follow-up specific attrition weights, calculated as the inverse of the probability of responding at each age based on covariates measured at age 18 (cohort, region of country, gender, race/ethnicity, parental education, number of parents in the home, religiosity, college plans, high school grades, alcohol use, cigarette use, marijuana use, and sampling weight correcting for oversampling of age 18 substance users).

\section{RESULTS}

\section{Descriptive Background: Age-Related Changes in Binge Drinking}

Figure 1 presents the estimated prevalence of binge drinking from ages 18 to 30 among all respondents (i.e., all high school cohorts 1976 to 2004) from an intercept-only TVEM. Binge drinking prevalence rose from $32.2 \%$ (99\% CI 31.6, $32.7)$ at age 18 to a peak of $40.8 \%(40.2,41.4)$ at age 21 and then decreased gradually across the remainder of young adulthood, reaching $28.3 \%(27.4,29.2)$ by age 30 . This overall developmental pattern has been reported previously (e.g., Patrick and Schulenberg, 2011; Schulenberg et al., 2018). The current study sought to identify gender and cohort variations in this pattern.

\section{Gender-by-Cohort Interactions in the Age-Related Pattern of Binge Drinking}

To examine the main research questions, models regressing binge drinking on cohort, gender, and gender-by-cohort interactions were examined. There was evidence of significant gender-by-cohort moderation in the developmental patterns of binge drinking. In the model using 1976 to 1985 as the referent cohort group, the male*1986 to 1995 interaction term was significant from ages 18 through 22, and the male*1996 to 2004 interaction term was significant at all ages. In the model using 1996 to 2004 as the referent group, the male*1986 to 1995 interaction term was significant at age 18 as well as ages 21 through 30 . Therefore, to address our research questions pertaining to gender-specific cohort differences in developmental patterns and to increase the interpretability of resulting figures, the analysis proceeded with gender-specific models regressing binge drinking on cohort. Figure 2 presents modeled estimates of binge drinking prevalence from ages 18 through 30 separately by cohort group for women and men. TVEM results regressing binge drinking on cohort groups separately for women and men are presented in Figs 3 and 4, respectively.

\section{Modeled Prevalence of Peak Age of Binge Drinking by Gender and Cohort}

As Fig. 2 shows, the pattern of binge drinking across age for both men and women in all cohort groups was best described as increasing from age 18 through varying ages in 


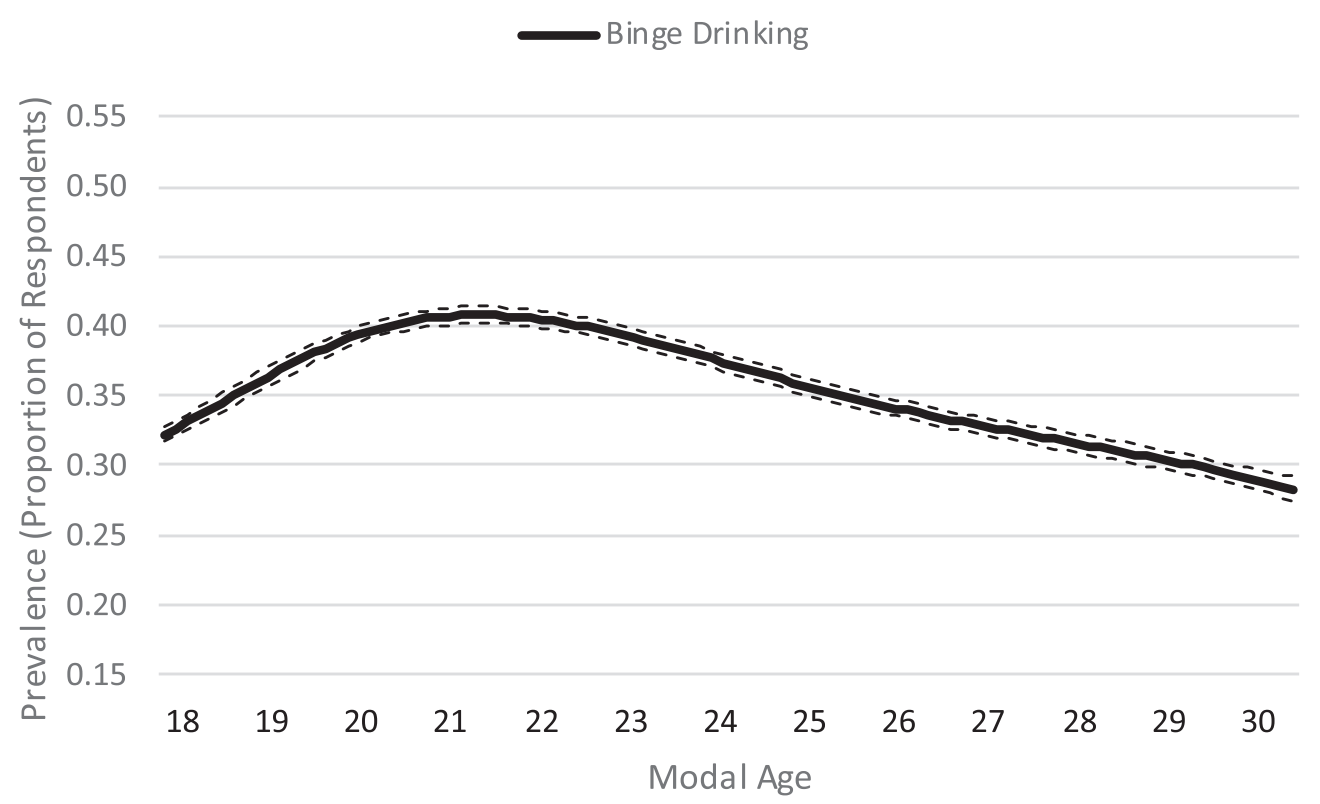

Fig. 1. Modeled prevalence of binge drinking among U.S. young adults aged 18 through 30 (from 12th-grade cohorts 1976 to 2004 combined). Notes: $N$ (unwtd.) $=306,814$ time points from 58,019 individuals. Estimates obtained from time-varying effect models. Dashed lines indicate $99 \%$ confidence intervals. Binge drinking defined as having $5+$ drinks in a row at least once during the past 2 weeks.

the early 20 s when an inflection point was reached, followed by decreasing prevalence thereafter (through age 30). For women, binge drinking prevalence for the 1976 to 1985 cohort group peaked at age 20 (specifically, age $19.70^{1}$ at 32 . $36 \%$ [31.16, 33.59]), for the 1986 to 1995 group at age 21 (specifically, age 20.55 at $29.55 \%$ [28.39, 30.74]), and for the 1996 to 2004 group at age 22 (specifically, age 21.64 at $33.29 \%$ [32.02, 34.59]). For men, binge drinking prevalence for the 1976 to 1995 cohort group peaked at age 21 (specifically, age 20.67 at $54.14 \%[52.76,55.51]$ ), for the 1986 to 1995 group at age 22 (specifically, age 21.76 at $50.41 \%$ [48.88, 51.93]), and for the 1996 to 2004 group at age 23 (specifically, age 22.97 at $51.40 \%$ [49.54, 53.26]).

\section{Modeled Cohort Differences in the Age-Related Pattern of Binge Drinking}

Comparing the Earliest High School Cohorts (1976 to 1985) to More Recent Cohorts (1986 to 1995 and 1996 to 2004). The odds of binge drinking were significantly lower for individuals in the 1986 to 1995 cohort group (vs. the 1976 to 1985 group) at ages 18 to 21 for women (Fig. 3) and ages 18 to 22 for men (Fig. 4), and statistically similar thereafter (differences were significantly larger for men than women). The odds of binge drinking for individuals in the 1996 to 2004 cohort group (vs. the 1976 to 1985 group) were significantly lower at ages 18 to 19 for women and ages 18 to

\footnotetext{
${ }^{1}$ Readers are reminded that TVEM reports estimates using smoothed points along continuous age; the default of 100 points has been used in these analyses, and thus, the specific peak age is noninteger. Rounding is used for most age reporting in the current paper, but for these analyses which focus on historical change in peak age across cohorts, we also provide specific values.
}

21 for men, and significantly higher at ages 22 to 30 for women and 25 to 28 for men (differences were significantly larger for men during early young adulthood, but significantly larger for women during later young adulthood).

Comparing the Most Recent High School Cohorts (1996 to 2004) Versus the Earlier Cohorts (1976 to 1985 and 1986 to 1995). The odds of binge drinking were significantly higher for individuals in the 1986 to 1995 cohort group (vs. the 1996 to 2004 group) at age 18 for men, and significantly lower at ages 20 to 30 for women and 24 to 28 for men (again, men had significantly larger cohort differences at early ages, while women had significantly larger cohort differences at later ages). Among women, the magnitude of difference between the 1996 to 2004 cohort group versus other cohort groups grew consistently from ages 20 through 24 , and then generally stabilized (at ages 24 to 30, 1976 to 1985 cohort group OR ranged 0.68 to $0.69 ; 1986$ to 1995 cohort group OR ranged 0.72 to 0.74 ). Binge drinking prevalence in the 1996 to 2004 cohort group was statistically higher than in all other cohort groups at ages 21 to 30 for women. In contrast, binge drinking prevalence in the 1996 to 2004 cohort group was statistically higher than in all other cohort groups only at ages 25 to 28 for men. Among men, the magnitude of difference between the 1996 to 2004 cohort group versus other cohort groups gradually increased at ages 24 to 27 (reaching a maximum OR of $0.86[0.77,0.95]$ for the 1976 to 1995 cohort group, and 0.85 [0.77, 0.95] for the 1986 to 1995 cohort group), and then gradually decreased during ages 27 to 28 .

Stability of Cohort Associations Within Gender from Ages 19 to 30 After Controlling for Covariates. After controlling for covariates (race/ethnicity, college attendance, 

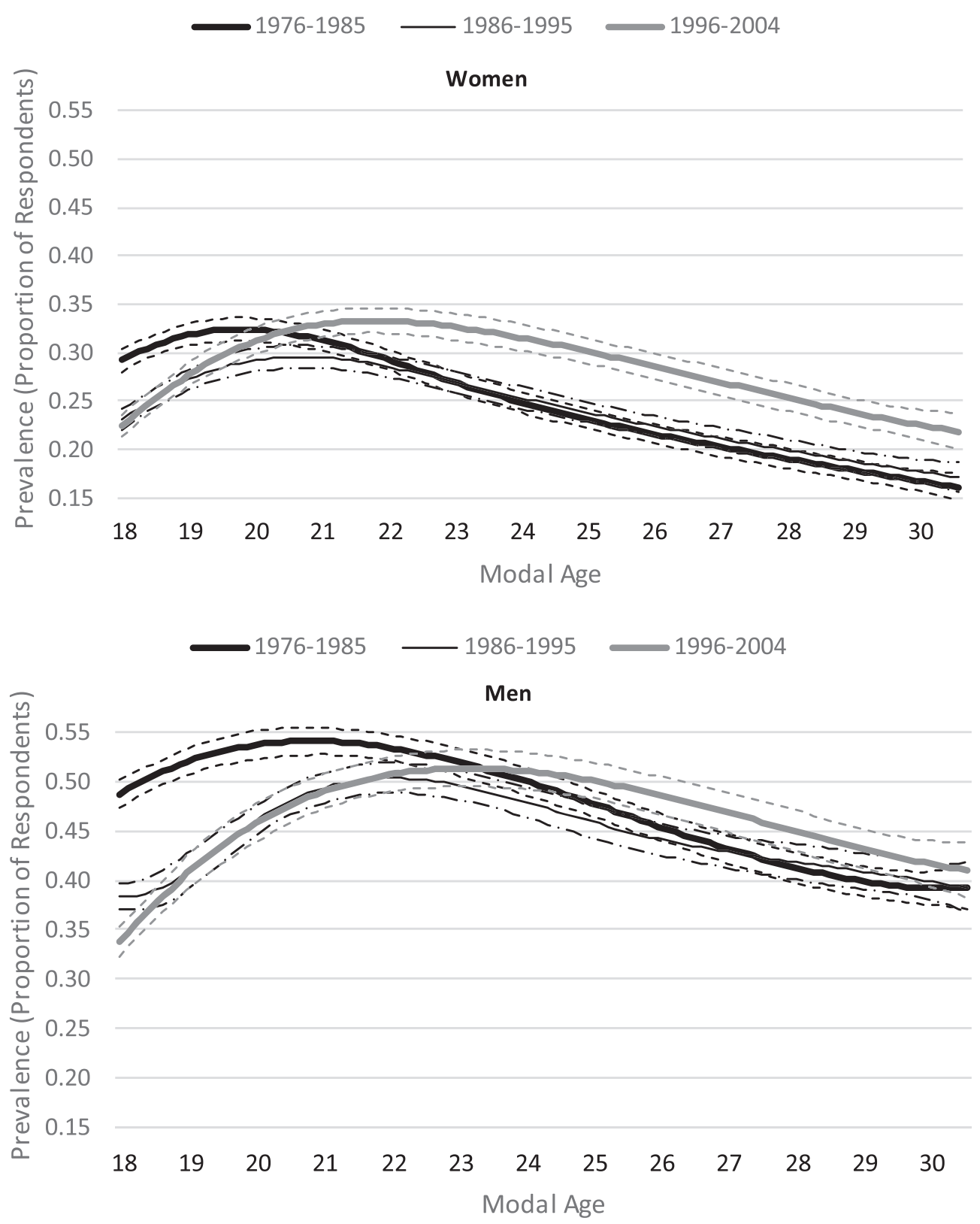

Fig. 2. Modeled prevalence of binge drinking by gender among U.S. young adults aged 18 through 30 by cohort groups. Notes: $N($ unwtd.) $=181,140$ time points from 31,156 women; 135,674 time points from 26,863 men. Estimates obtained from time-varying effect models. Dashed lines indicate $99 \%$ confidence intervals. Binge drinking defined as having $5+$ drinks in a row at least once during the past 2 weeks.

employment, marital status, parental status, and MLDA), within-gender cohort group differences showed some degree of attenuation, but the overall findings remained-particularly for later young adulthood (see Figs S1 and S2). With the earliest high school cohorts (1976 to 1985) as referent, the adjusted odds of binge drinking remained significantly lower for the 1986 to 1995 cohort group, but only at age 19 for women and ages 19 to 20 for men. The adjusted odds of binge drinking were no longer significantly lower for women in the 1996 to 2004 versus 1976 to 1985 cohort groups at ages 18 to 19 , but were significantly higher for ages 21 to 30 . Among men, the adjusted odds of binge drinking for the 1996 to 2004 versus 1976 to 1985 cohort groups retained significance but at smaller age ranges: lower at ages 19 to 21 and higher at ages 25 to 27.

When using 1996 to 2004 as referent, the adjusted odds of binge drinking for those in the 1986 to 1995 cohort group remained significantly lower at ages 20 to 30 for women and 24 to 26 for men. The magnitude of difference between women in the 1996 to 2004 cohort group versus other cohort groups continued to show consistent growth through age 24, and then generally stabilized. Among women, the adjusted odds of binge drinking remained higher in the 1996 to 2004 cohort group than in all other groups from ages 21 to 30 ; these differences were found only at ages 25 to 26 for men. 

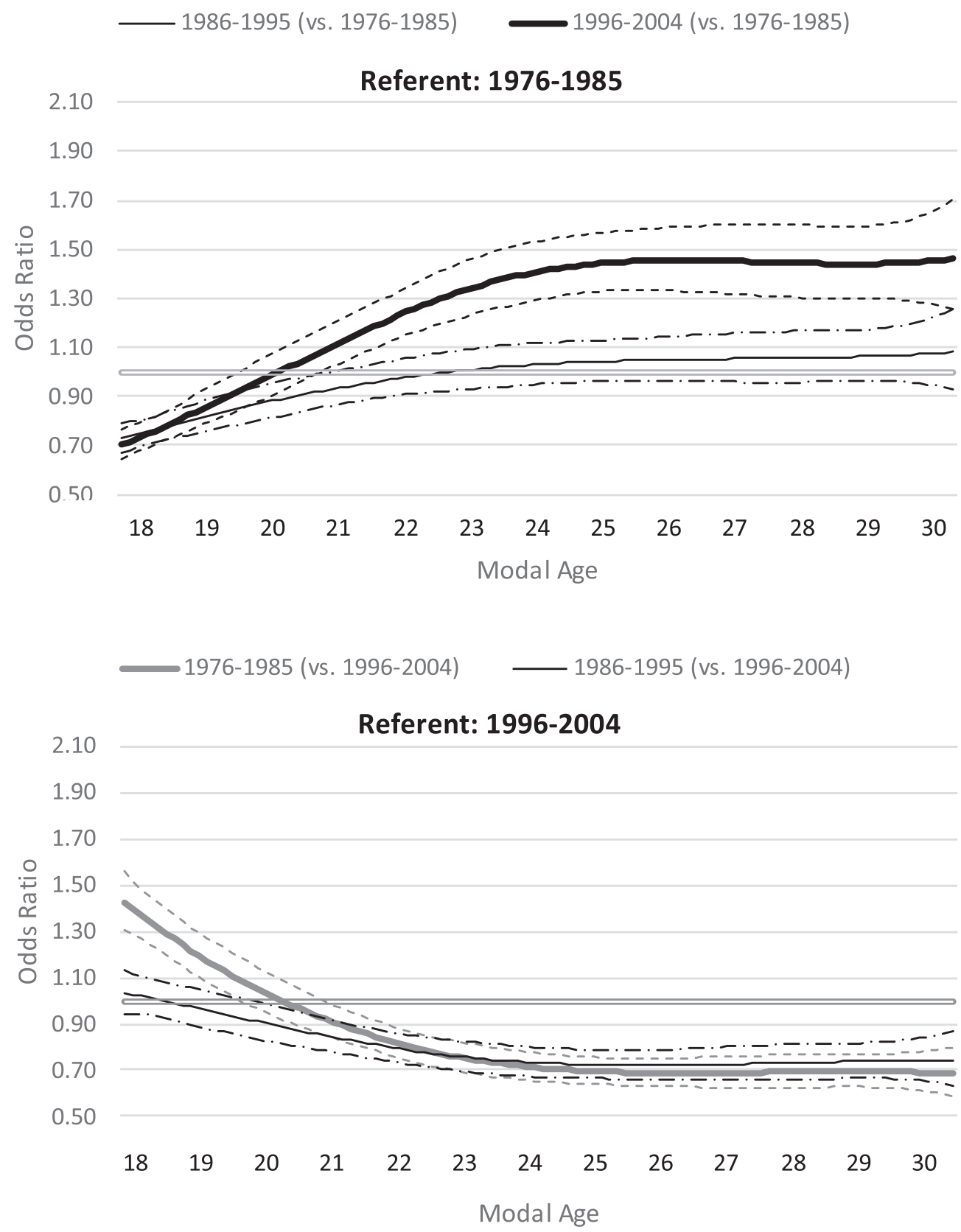

Fig. 3. Odds ratios and corresponding $99 \%$ confidence intervals to test for age-varying associations between cohort groups and the odds of binge drinking among U.S. young adult women aged 18 through 30. Notes: $N$ (unwtd.) = 181,140 time points from 31,156 women. Estimates obtained from time-varying effect models. Dashed lines indicate 99\% confidence intervals. Binge drinking defined as having 5+ drinks in a row at least once during the past 2 weeks.

Sensitivity Analyses. Sensitivity analyses were conducted to examine whether different findings emerged when examining the prevalence of multiple binge occasions within the past 2 weeks; resulting conclusions were substantively unchanged from those using any binge drinking.

\section{DISCUSSION}

The current study is the first to examine historical shifts in the peak age of binge drinking during young adulthood. Using multicohort national samples of U.S. young adults across 3 decades (12th-grade cohorts of 1976 to 2004, which equate approximately with birth cohorts of 1958 to 1986), we observed that the actual age of peak binge drinking prevalence has increased significantly across cohorts for both men and women. Within the 1976 to 1985 cohort group, binge drinking prevalence peaked at age 20 for women and 21 for men. Thereafter, peak age for women moved to 21 for the 1986 to 1995 cohorts, and then to 22 for the 1996 to 2004 cohorts. Among men, the peak age moved to age 22 and then to age 23 for cohort groups 1986 to 1995 and 1996 to 2004, respectively. Furthermore, historical changes in the course of binge drinking prevalence throughout young adulthood did not reflect a simple shift up the age spectrum. Rather, the 


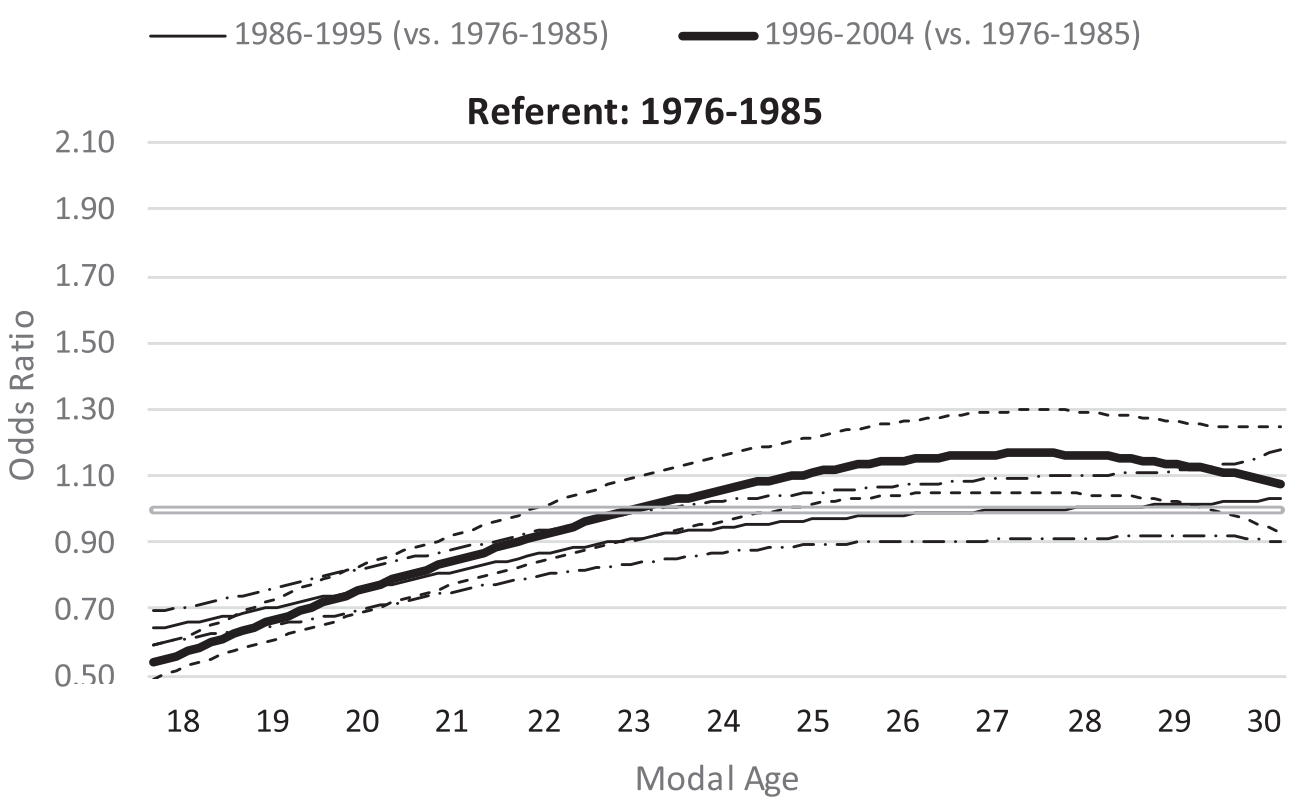

1976-1985 (vs. 1996-2004) _ - 1986-1995 (vs. 1996-2004)

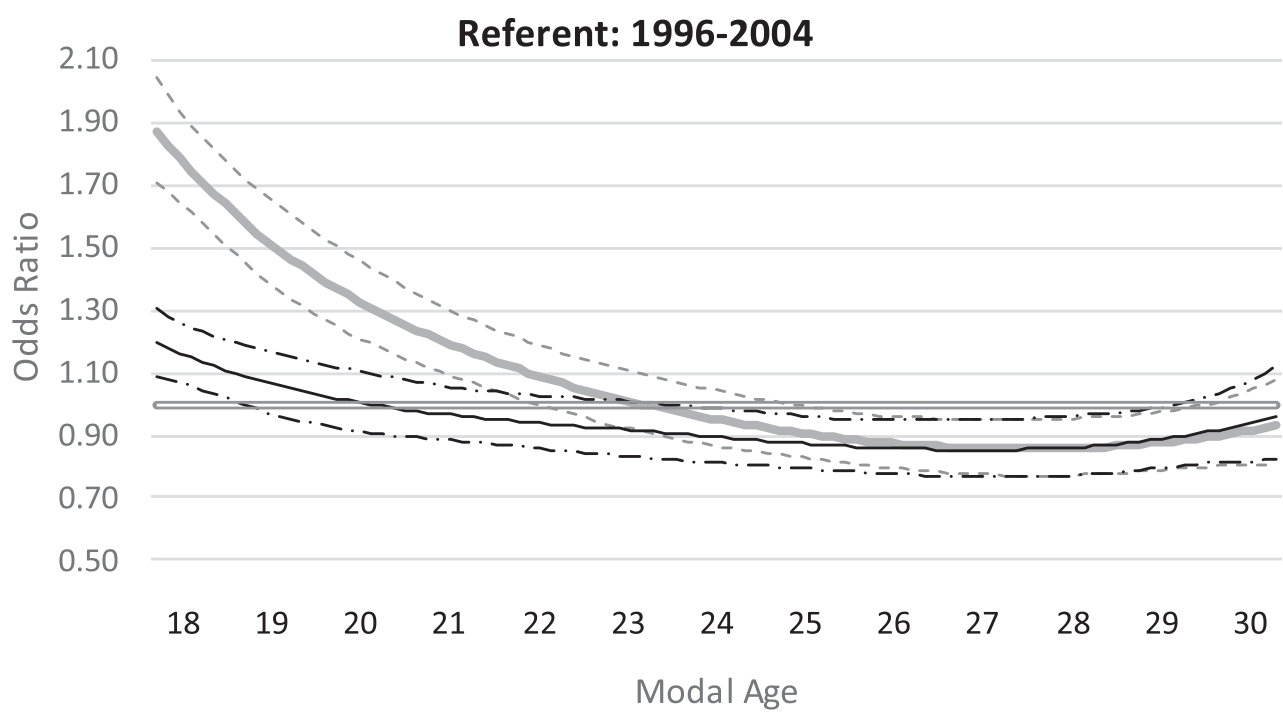

Fig. 4. Odds ratios and corresponding $99 \%$ confidence intervals to test for age-varying associations between cohort groups and the odds of binge drinking among U.S. young adult men aged 18 through 30 . Notes: $N$ (unwtd.) $=135,674$ time points from 26,863 men. Estimates obtained from time-varying effect models. Dashed lines indicate 99\% confidence intervals. Binge drinking defined as having 5+ drinks in a row at least once during the past 2 weeks.

age-related pattern of the increase, peak, and decrease in the prevalence of binge drinking changed and significantly varied by gender; such changes were not fully explained by controlling for policy, social role, and racial/ethnic covariates. These TVEM-based results for the prevalence of binge drinking from ages 18 to 30 extend prior research on the average frequency of binge drinking from ages 18 to 26 using latent growth curve modeling that showed cohort changes in agerelated increases and decreases (Jager et al., 2013, 2015).

Controlling for covariates somewhat attenuated the observed cohort group differences for ages 19 to 20, particularly for women (leaving significant differences between women in the 1976 to 1985 and 1986 to 1995 cohort groups only at age 19, and no significant differences between women in the 1976 to 1985 and 1996 to 2004 cohort groups at ages 19 to 20). However, even after controlling for covariates, the adjusted odds of binge drinking among women remained higher in the 1996 to 2004 cohort group than all other groups for ages 21 to 30, and among men for ages 25 to 26. These findings support those from prior research (Jager et al., 2015), which found that growth rates for binge drinking frequency were somewhat explained by 
MLDA and social roles only during early young adulthood. Thus, it appears that a fundamental shift in binge drinking behavior is occurring-particularly among women-during the mid- to late 20s. As new cohorts of high school graduates move through young adulthood, the course of binge drinking appears poised to reflect an even longer duration of increasing prevalence across late adolescence and early young adulthood than that observed in earlier cohorts, with a further delayed peak age. To the extent to which levels of binge drinking remain elevated into later ages, the elevated risks associated with binge drinking also extend further into young adulthood.

Meaningful gender differences were observed in the ways that the developmental patterns of binge drinking prevalence have changed across recent decades. In the current study, significant gender-by-cohort differences were found across all ages 18 through 30 for the most recent cohorts compared to earlier cohorts, including during the late 20 s which is a period of normative decline in binge drinking (Patrick and Schulenberg, 2011). In particular, from ages 21 through 30, women in the more recent cohort group (high school graduating classes of 1996 to 2004) had significantly higher binge drinking prevalence than women in earlier cohorts (1976 to 1985 and 1986 to 1995). However, the magnitude of difference between binge drinking prevalence among women in the 1996 to 2004 cohort group and prior cohort groups stabilized at age 24 , remaining generally consistent thereafter. Men in the more recent cohort group had higher binge drinking prevalence at ages 25 to 26 than men in earlier cohorts, but the prevalence of binge drinking converged to levels similar to those of earlier cohort groups by age 27 for men. Thus, while both men and women experienced a more rapid rate of acceleration in binge drinking prevalence from ages 18 through the mid-20s in the more recent cohort group versus earlier cohort groups (which supports prior research with binge drinking frequency through age 26; Jager et al., 2013, 2015), higher binge drinking prevalence continued for women in the more recent cohort group (vs. earlier cohorts) through age 30. In contrast, for men, cohort differences in binge drinking prevalence disappeared between ages 27 and 30 , such that by age 30 , binge drinking prevalence did not differ between the 1996 to 2004 cohorts and the prior cohorts.

Alcohol use during later young adulthood has received less research attention than the years of early- to mid-young adulthood. However, a gradual but generally steady historical increase in binge drinking prevalence among U.S. young adults at age 30 has been observed (Patrick et al., 2017b; Schulenberg et al., 2018). Future studies that can examine cohort differences in binge drinking into the 30s and beyond may find that, among women, binge drinking prevalence converges across cohort groups at a later age. However, extrapolating from the generally stable magnitude of difference in binge drinking prevalence for ages 24 to 30 between women in the more recent cohort group versus earlier cohort groups, binge drinking prevalence (and associated risks) may remain elevated among women in the more recent cohorts past age 30 .

The consistently higher likelihood of binge drinking for women-but not men-in the most recent cohort group compared with earlier cohorts from ages 21 through 30 is consistent with the narrowing gender gap in alcohol use that has largely been driven by increases among women (Slade et al., 2016). Further, the current study's findings support projections of decreases in alcohol use from middle age onward to be weaker for women than men (Karlamangla et al., 2006). As mentioned above, social role changes appear to have some level of explanatory role (e.g., delayed childbearing has been shown to be associated with significantly increased generational odds of heavy alcohol consumption in longitudinal studies of mother-daughter dyads; Alati et al., 2014). Key historical differences in alcohol industry product development and marketing also may have played a meaningful role, with concerted efforts by the alcohol industry to develop products and campaigns specifically targeting women (Alcohol Beverage Retail, 2018; European Centre for Monitoring Alcohol Marketing, 2008; Parsons, 2010). Marketing for a range of alcohol products to women has increased notably and-for women in the more recent cohort groups-may be leading to increased binge drinking (Kindy and Keating, 2016) through age 30 and possibly beyond.

\section{Limitations and Strengths}

The findings of the current study should be considered within their limitations. The current analysis relied on repeated nationally representative samples of 12 th-grade students, thus excluding those who dropped out of school prior to 12th grade (school dropout is associated with increased binge drinking; Tice et al., 2017). Further, all data were selfreport, used a general measure of 5+ drinks for both men and women (rather than gender-specific levels of $4+$ for women and $5+$ drinks for men per occasion [e.g., Centers for Disease Control and Prevention, 2015; Kann et al., 2018]), and focused on binge drinking within a relatively short time frame (i.e., past 2 weeks). However, in 2013, the MTF prevalence estimate for past 2 week binge was $35.1 \%$ for individuals aged 19 to 28 (Schulenberg et al., 2018), which is comparable to $37.9 \%$ for past month binge prevalence among individuals aged 18 to 25 in the National Survey on Drug Use and Health (Center for Behavioral Health Statistics and Quality, 2015), and $25.8 \%$ for past month binge prevalence among those 18 and older in the National Epidemiologic Survey on Alcohol and Related Conditions III (Dawson et al., 2015). Finally, attrition across young adulthood is a limitation, somewhat mitigated by adjustments via weighting. However, the current analysis has a number of important strengths, particularly utilization of national longitudinal data with cohorts that have been assessed with consistent measurement across 3 decades. The use of TVEM has allowed models to focus on complex associations between 
both gender and cohort across age without the assumption of parametric associations or the a priori need to specify inflection points. The study is the first to show that the peak age of binge drinking prevalence is increasing during young adulthood.

\section{Implications and Conclusions}

The results of the current study highlight that the developmental course of alcohol use has varied in important ways across adjacent cohorts and underscores the fact that historical change in etiology can occur relatively rapidly. With such changes in course, other components of etiology-including risk factors and consequences of alcohol use - are also shifting, and these are important directions for future research (Schulenberg et al., 2014). The observed delays in the peak age of binge drinking frequency and elevated prevalence levels of such drinking into the late 20s for men and women have important theoretical and practical implications. While it remains the case that binge drinking prevalence tends to escalate after high school, peak during the early 20 s, and then decline, there are also fundamental shifts in the shape of these developmental patterns. The peak age has shifted upward by 2 years over the past 3 decades (from age 20 to 22 for women, and from age 21 to 23 for men). In addition, women in the more recent cohort groups more commonly report binge drinking through age 30 , while men in these same cohorts are returning to prevalence levels similar to those from earlier cohorts by age 30 . Both of these fundamental shifts result in an extension of individual and societal risks associated with binge drinking into and throughout the 20s. The extent to which historical variation in the peak age of binge drinking prevalence found here generalizes to other binge drinking indicators, including binge drinking frequency and high-intensity (or extreme binge) drinking (Patrick et al., 2016, 2017b), is not clear. Consequently, future research should examine the extent to which peak age varies historically for these other indicators. The majority of alcohol prevention and intervention efforts have focused on adolescents and early college student populations, but the current findings underscore the need to extend intervention efforts to young adults more broadly and increasingly to women. There is a need to ensure that high-risk alcohol intervention efforts are developed and implemented to reach individuals throughout the third decade of life, and to alert clinicians to the importance of screening for alcohol-related problems throughout this key developmental period.

\section{ACKNOWLEDGMENTS}

Development of this manuscript was supported by research grants from the National Institute on Alcohol Abuse and Alcoholism (R01AA023504 to MEP and R01AA026861 to JJ and K. Keyes) and the National Institute on Drug Abuse (R01DA037902 to MEP and R01DA039854 to STL). Data collection and manuscript preparation were also supported by the National Institute on Drug Abuse (through research grants R01DA001411 to R. Miech and L. Johnston and R01DA016575 to JES and L. Johnston). The study sponsors had no role in the study design, collection, analysis, or interpretation of the data, writing of the manuscript, or the decision to submit the paper for publication. The content is solely the responsibility of the authors and does not necessarily represent the official views of the study sponsor. The authors declare no conflicts of interest.

\section{REFERENCES}

Alati R, Betts KS, Williams GM, Najman JM, Hall WD (2014) Generational increase in young women's drinking: a prospective analysis of motherdaughter dyads. JAMA Psychiatry 71:952-957.

Alcohol Beverage Retail (2018) How male-driven alcohol brands are pivoting to target women more effectively (April 16). Available at: https:// www.gospotcheck.com/2018/04/16/how-male-driven-alcohol-brands-arepivoting-to-target-women-more-effectively/. Accessed December 26, 2018.

Alfonso-Loeches S, Guerri C (2011) Molecular and behavioral aspects of the actions of alcohol on the adult and developing brain. Crit Rev Clin Lab Sci 48:19-47.

Bachman JG, Johnston LD, O'Malley PM, Schulenberg JE, Miech RA (2015) The Monitoring the Future Project After Four Decades: Design and Procedures (Monitoring the Future Occasional Paper No. 82). Institute for Social Research, Ann Arbor, MI. Available at: http://monitoringthefuture. org/pubs/occpapers/mtf-occ82.pdf. Accessed December 26, 2018.

Bachman JG, O’Malley PM, Schulenberg JE, Johnston LD, Bryant AL, Merline AC (2002) The Decline of Substance Use in Young Adulthood: Changes in Social Activities, Roles, and Beliefs. Lawrence Erlbaum Associates, Mahwah, NJ.

Bachman JG, Wadsworth KN, O'Malley PM, Johnston LD, Schulenberg JE (1997) Smoking, Drinking, and Drug Use in Young Adulthood: The Impacts of New Freedoms and New Responsibilities. Lawrence Erlbaum Associates, Mahwah, NJ.

Center for Behavioral Health Statistics and Quality (2015) Behavioral Health Trends in the United States: Results from the 2014 National Survey on Drug Use and Health (HHS Publication No. SMA 15-4927, NSDUH Series H-50). Available at: https://www.samhsa.gov/data/sites/default/files/ NSDUH-FRR1-2014/NSDUH-FRR1-2014.pdf. Accessed December 26, 2018.

Centers for Disease Control and Prevention (2015) BRFSS Prevalence \& Trends Data [online]. National Center for Chronic Disease Prevention and Health Promotion. Available at: https://www.cdc.gov/brfss/brfssprevalence/ . Accessed December 26, 2018.

Centers for Disease Control and Prevention (2017) Binge Drinking. Available at: https://www.cdc.gov/alcohol/fact-sheets/binge-drinking.htm. Accessed December 26, 2018.

Conrod PJ, Castellanos N, Mackie C (2008) Personality-targeted interventions delay the growth of adolescent drinking and binge drinking. J Child Psychol Psychiatry 49:181-190.

Crego A, Holguin SR, Parada M, Mota N, Corral M, Cadaveira F (2009) Binge drinking affects attentional and visual working memory processing in young university students. Alcohol Clin Exp Res 33:1870-1879.

Dawson DA, Goldstein RB, Saha TD, Grant BF (2015) Changes in alcohol consumption: United States, 2001-2002 to 2012-2013. Drug Alcohol Depend 148:56-61.

Delker E, Brown Q, Hasin DS (2016) Alcohol consumption in demographic subpopulations: an epidemiologic overview. Alcohol Res 38:7-15.

Dir AL, Bell RL, Adams ZW, Hulvershorn LA (2017) Gender differences in risk factors for adolescent binge drinking and implications for intervention and prevention. Front Psychiatry 8:289. 
Dziak JJ, Lanza ST, Tan X (2014) Effect size, statistical power and sample size requirements for the bootstrap likelihood ratio test in latent class analysis. Struct Equ Model 21:534-552.

Dziak JJ, Li R, Wagner AT (2017) Weighted TVEM SAS Macro Users' Guide (Version 2.6). University Park, PA, The Methodology Center, Penn State. Available at: http://methodology.psu.edu. Accessed December 26, 2018.

Erol A, Karpyak VM (2015) Sex and gender-related differences in alcohol use and its consequences: contemporary knowledge and future research considerations. Drug Alcohol Depend 156:1-13.

European Centre for Monitoring Alcohol Marketing (2008) Women: The New Market. Trends in Alcohol Marketing. Available at: http://eucam.inf o/wp-content/uploads/2014/05/women_the_new_market_final.pdf. Accessed December 26, 2018.

Hedlund JH, Ulmer RG, Preusser DF (2001) Determine Why There Are Fewer Young Alcohol-Impaired Drivers. Final Report. DOT HS 809348. US Department of Transportation, National Highway Traffic Safety Administration, Washington, DC. Available at: https://one.nhtsa.gov/peo ple/injury/research/FewerYoungDrivers/index.htm. Accessed December 26, 2018.

Hoxie P, Skinner D (1987) A Statistical Analysis of the Effects of a Uniform Minimum Drinking Age. US Department of Transportation, National Highway Traffic Safety Administration, Washington, DC. Available at: https://rosap.ntl.bts.gov/view/dot/8611. Accessed December 26, 2018.

Jager J, Keyes KM, Schulenberg JE (2015) Historical variation in young adult binge drinking trajectories and its link to historical variation in social roles and minimum legal drinking age. Dev Psychol 51:962-974.

Jager J, Schulenberg JE, O’Malley PM, Bachman JG (2013) Historical variation in drug use trajectories across the transition to adulthood: the trend toward lower intercepts and steeper, ascending slopes. Dev Psychopathol 25:527-543.

Kann L, McManus T, Harris WA, Shanklin SL, Flint KH, Queen B, Lowry R, Chyen D, Whittle L, Thornton J, Lim C, Bradford D, Yamakawa Y, Leon M, Brener N, Ethier K (2018) Youth risk behavior surveillance United States, 2017. MMWR Surveill Summ 67:1-114.

Karlamangla A, Zhou K, Reuben D, Greendale G, Moore A (2006) Longitudinal trajectories of heavy drinking in adults in the United States of America. Addiction 101:91-99.

Kerr WC, Greenfield TK, Bond J, Ye Y, Rehm J (2009) Age-period-cohort modelling of alcohol volume and heavy drinking days in the US National Alcohol Surveys: divergence in younger and older adult trends. Addiction 104:27-37.

Khandwala YS, Zhang CA, Lu Y, Eisenberg ML (2017) The age of fathers in the USA is rising: an analysis of 168867480 births from 1972 to 2015. Hum Reprod 32:2110-2116.

Kindy K, Keating D (2016) For women, heavy drinking has been normalized. That's dangerous. The Washington Post, December 23. Available at: https://www.washingtonpost.com/national/for-women-heavy-drinking-ha s-been-normalized-thats-dangerous/2016/12/23/0e701120-c381-11e6-95780054287507 db_story.html?utm_term $=$. e463fae6d392. Accessed December 20, 2018.

Lanza ST, Vasilenko S, Liu X, Li R, Piper ME (2014) Advancing the understanding of craving during smoking cessation attempts: a demonstration of the time-varying effect model. Nicotine Tob Res 16:S127-S134.

Lanza ST, Vasilenko SA, Russell MA (2016) Time-varying effect modeling to address new questions in behavioral research: examples in marijuana use. Psychol Addict Behav 30:939-954.

Lebel C, Beaulieu C (2011) Longitudinal development of human brain wiring continues from childhood into adulthood. J Neurosci 31:1093710947.

Li R, Dziak JD, Tan X, Huang L, Wagner AT, Yang J (2015) TVEM (TimeVarying Effect Modeling) SAS Macro Users' Guide (Version 3.1.0). University Park, The Methodology Center, Penn State. Available at: http://methodology.psu.edu. Accessed December 26, 2018.

Maggs JL, Schulenberg JE (2004) Trajectories of alcohol use during the transition to adulthood. Alcohol Res Health 28:195-201.
Mathews TJ, Hamilton BE (2016) Mean age of mothers is on the rise: United States, 2000-2014. NCHS Data Brief (232):1-8.

Matthews TJ, Hamilton BE (2009) Delayed childbearing: more women are having their first child later in life. NCHS Data Brief (21): 1-8.

Miech RA, Johnston LD, O'Malley PM, Bachman JG, Schulenberg JE, Patrick ME (2018) Monitoring the Future National Survey Results on Drug use, 1975-2017: Volume I, Secondary School Students. Institute for Social Research, University of Michigan, Ann Arbor. Available at: http://monitoringthefuture.org/pubs/monographs/mtf-vol1_2017.pdf.

Accessed December 26, 2018.

Naimi TS, Lipscomb LE, Brewer RD, Gilbert BC (2003) Binge drinking in the preconception period and the risk of unintended pregnancy: implications for women and their children. Pediatrics 111:1136-1141.

National Center for Education Statistics (2018) US College Enrollment Statistics for Public and Private Colleges from 1965 to 2016 and Projections up to 2017 (in Millions). US Department of Education. Available at: https://www.statista.com/statistics/183995/us-college-enrollment-and-pro jections-in-public-and-private-institutions/. Accessed December 26, 2018.

O’Malley PM, Wagenaar AC (1991) Effects of minimum drinking age laws on alcohol use, related behaviors and traffic crash involvement among American youth: 1976-1987. J Stud Alcohol 52:478-491.

Parsons R (2010) Can the alcohol industry truly tap into what women want? Marketing Week, March 26. Available at: https://www.marketingweek. com/2010/03/26/can-the-alcohol-industry-truly-tap-into-what-womenwant/. Accessed December 10, 2018.

Patrick ME, Evans-Polce R, Kloska DD, Maggs JL, Lanza ST (2017a) Agerelated changes in associations between reasons for alcohol use and highintensity drinking across young adulthood. J Stud Alcohol Drugs 78:558570.

Patrick ME, Schulenberg JE (2011) How trajectories of reasons for alcohol use relate to trajectories of binge drinking: national panel data spanning late adolescence to early adulthood. Dev Psychol 47:311-317.

Patrick ME, Terry-McElrath YM, Kloska DD, Schulenberg JE (2016) Highintensity drinking among young adults in the United States: prevalence, frequency, and developmental change. Alcohol Clin Exp Res 40:19051912.

Patrick ME, Terry-McElrath YM, Miech RA, Schulenberg JE, O'Malley PM, Johnston LD (2017b) Age-specific prevalence of binge and highintensity drinking among U.S. young adults: changes from 2005 to 2015 . Alcohol Clin Exp Res 41:1319-1328.

Pew Research Center (2015) Estimated U.S. Population by Race and Hispanic Origin, 1965-2015, with and without Immigrants Entering 1965-2015, Pew Research Center. Available at: http://www.pewhispanic.org/2015/09/ 28/modern-immigration-wave-brings-59-million-to-u-s-driving-populationgrowth-and-change-through-2065/ph_2015-09-28_immigration-through2065-a2-05/. Accessed December 26, 2018.

Pujol J, Vendrell P, Junque C, Marti-Vilalta JL, Capdevila A (1993) When does human brain development end? Evidence of corpus callosum growth up to adulthood. Ann Neurol 34:71-75.

Schulenberg J, Patrick ME, Maslowsky J, Maggs JL (2014) The epidemiology and etiology of adolescent substance use in developmental perspective, in Handbook of Developmental Psychopathology. 3rd ed. (Lewis M, Rudolph K eds), pp 601-620. Springer, New York, NY.

Schulenberg JE, Johnston LD, O’Malley PM, Bachman JG, Miech RA, Patrick ME (2018) Monitoring the Future National Survey Results on Drug Use, 1975-2017: Volume II, College Students and Adults Ages 1955. Institute for Social Research, The University of Michigan, Ann Arbor, MI. Available at: http://monitoringthefuture.org/pubs.html\#monographs. Accessed December 26, 2018.

Slade T, Chapman C, Swift W, Keyes K, Tonks Z, Teesson M (2016) Birth cohort trends in the global epidemiology of alcohol use and alcohol-related harms in men and women: systematic review and metaregression. BMJ Open 6.

Sowell ER, Thompson PM, Holmes CJ, Jernigan TL, Toga AW (1999) In vivo evidence for post-adolescent brain maturation in frontal and striatal regions. Nat Neurosci 2:859-861. 
Squeglia LM, Pulido C, Wetherill RR, Jacobus J, Brown GG, Tapert SF (2012) Brain response to working memory over three years of adolescence: influence of initiating heavy drinking. J Stud Alcohol Drugs 73:749-760.

Substance Abuse and Mental Health Services Administration (2017) Key Substance Use and Mental Health Indicators in the United States: Result from the 2016 National Survey on Drug Use and Health (HHS Publication No. SMA 17-5044, NSDUH Series H-52). Center for Behavioral Health Statistics and Quality, Substance Abuse and Mental Health Services Administration, Rockville, MD.

Substance Abuse and Mental Health Services Administration (2018) Binge Drinking: Terminology and Patterns of Use. Center for the Application of Prevention Technologies, Substance Abuse and Mental Health Services Administration, Rockville, MD.

Tamnes CK, Ostby Y, Fjell AM, Westlye LT, Due-Tonnessen P, Walhovd KB (2010) Brain maturation in adolescence and young adulthood: regional age-related changes in cortical thickness and white matter volume and microstructure. Cereb Cortex 20:534-548.

Tan X, Shiyko MP, Li R, Li Y, Dierker L (2012) A time-varying effect model for intensive longitudinal data. Psychol Methods 17:61-77.

Taylor P, Parker K, Kochhar R, Fry R, Funk C, Patten E, Motel S (2012) Young, Underemployed and Optimistic: Coming of age, Slowly, in a Tough Economy. Pew Research Center, Washington, DC. Available at: http://assets.pewresearch.org/wp-content/uploads/sites/3/2012/02/youngunderemployed-and-optimistic.pdf. Accessed December 26, 2018.

Terry-McElrath YM, Patrick ME (2018) U.S. adolescent alcohol use by race/ethnicity: consumption and perceived need to reduce/stop use. J Ethn Subst Abuse doi: 10.1080/15332640.2018.1433094 [Epub ahead of print].

Tice P, Lipari RN, Van Horn SL (2017) Substance use Among 12th Grade Aged Youths, by Dropout Status. The CHBSQ Report. Center for Behavioral Health Statistics and Quality, Substance Abuse and Mental Health Services Administration, Rockville, MD. Available at: https://www.sa mhsa.gov/data/sites/default/files/report_3196/ShortReport-3196.pdf. Accessed December 26, 2018.

US Bureau of Labor Statistics (2004-2017). Tables on Employment Status of the Civilian Noninstitutional Population, by Age and Gender, Annual Averages from 2002 and 2004-2016. Obtained from Annual Publications of Annual Report: Women in the Labor Force: A Databook. Available at: https://www.bls.gov/cps/demographics.htm. Accessed December 26, 2018.

US Census Bureau (2017) Median Age at First Marriage: 1890 to Present. Available at: https://www.census.gov/content/dam/Census/library/visual izations/time-series/demo/families-and-households/ms-2.pdf. Accessed December 26, 2018.
Wagenaar AC, Toomey TL (2002) Effects of minimum drinking age laws: review and analyses of the literature from 1960 to 2000. J Stud Alcohol Suppl s4: 206-225.

Walhovd KB, Fjell AM, Reinvang I, Lundervold A, Dale AM, Eilertsen DE, Quinn BT, Salat D, Makris N, Fischl B (2005) Effects of age on volumes of cortex, white matter and subcortical structures. Neurobiol Aging 26: 1261-1270; discussion 1275-1278.

Weighted TVEM SAS Macro (2017) Weighted TVEM SAS Macro (Version 2.6.0) [Software], University Park, PA, The Methodology Center, Penn State. Available at: http://methodology.psu.edu. Accessed December 26, 2018.

White A, Castle I-JP, Chen CM, Shirley M, Roach D, Hingson R (2015) Converging patterns of alcohol use and related outcomes among females and males in the United States, 2002 to 2012. Alcohol Clin Exp Res 39:1712-1726.

Wood MD, Fairlie AM, Fernandez AC, Borsari B, Capone C, Laforge R, Carmona-Barros R (2010) Brief motivational and parent interventions for college students: a randomized factorial study. J Consult Clin Psychol 78:349-361.

World Health Organization (2014) Global Status Report on Alcohol and Health, 2014. World Health Organization, Geneva, Switzerland. Available at: http://www.who.int/substance_abuse/publications/global_alco hol_report/msb_gsr_2014_1.pdf. Accessed December 26, 2018.

\section{SUPPORTING INFORMATION}

Additional supporting information may be found online in the Supporting Information section at the end of the article.

Fig. S1. Adjusted ORs and corresponding 99\% CIs to test for age-varying associations between cohort groups and the odds of binge drinking among U.S. young adult women aged 19 through 30 .

Fig. S2. Adjusted ORs and corresponding $99 \%$ CIs to test for age-varying associations between cohort groups and the odds of binge drinking among U.S. young adult men aged 18 through 30 .

Table S1. Differences in binge drinking and covariates between cohort groups. 